Franz Haas

Andres Suárez

Franci Cus

Uros Zuperl

https://doi.org/10.21278/TOF.43203

ISSN 1333-1124

eISSN 1849-1391

\title{
PLATFORM FOR MONITORING AND COMPARING MACHINING PROCESSES IN TERMS OF ENERGY EFFICIENCY
}

\begin{abstract}
Summary
This paper presents a smart energy consumption monitoring platform for machining processes with a unique electrical energy consumption indicator (EECI) for the evaluation and comparison of machining processes in terms of energy efficiency. The purpose of the developed smart monitoring platform with the integrated EECI and the Industry 4.0 digital technologies is to raise the level of efficiency of the machining process and thus to stimulate more sustainable and environmentally friendly machining. The energy consumption monitoring of a milling process is performed by connecting a machine tool with integrated sensors for measuring electrical power and cutting force to a cloud platform by using resources for signal acquiring and data acquisition. The platform includes applications for energy consumption monitoring and/or analysis. Results of four machining experiments are presented to demonstrate the effectiveness of the proposed energy consumption monitoring in machining and the applicability of the newly introduced EECI at the engineering and the operational level.
\end{abstract}

Key words: $\quad$ machining, milling, energy efficiency, smart monitoring, electrical energy consumption indicator.

\section{Introduction}

Energy efficiency is becoming an increasingly important issue in modern tool making companies, especially due to continuous efforts to reduce machining costs. It is also of significance for upper management because achieving energy efficiency stimulates the careful energy management to accomplish increasingly sustainable and environmentally friendly machining. The energy efficiency improvement is also a vital issue to be tackled by governments. The governments are responsible for preparing protocols and developing strategies which help minimizing $\mathrm{CO}_{2}$ emissions and environmental footprints. A regulatory framework called Energy 2020 was adopted in 2007. This European Union regulation set a goal to lower emissions by at least $20 \%$ by 2020 [1]. It is estimated that approximately one trillion Euros are required to meet this objective [1]. Increasing energy production prices and government directives have a significant impact on the further technological development and investment in the equipment of tool making companies as the only efficient way to reduce emissions and energy consumption is the modernization of equipment and infrastructure [2, 3]. 
One way to modernize equipment and infrastructure is to implement Industry 4.0 technologies into machining processes. According to the Industry 4.0 agenda, digital technologies have a potential to rise machining to a higher, more efficient level. Modern, upto-date machine tools contain numberless smart sensors and subsystems. These advanced mechatronic systems can acquire, pre-process and transfer an increased amount of process data to the cloud-based monitoring and control applications. Therefore, there is a practical need to develop applications for monitoring and analyzing the energy consumption of machining processes and thus to support managers' decisions that will beneficially affect the company's development.

In this paper, a unique and not yet published electrical energy consumption indicator (EECI) for the evaluation and comparison of energy efficiency of processes is introduced. The applicability of the EECI integrated in a monitoring process is explained in detail on a milling process. However, the EECI is designed with the goal of expanding it to other subtractive formative and additive processes. In the future, the EECI could be used for the evaluation of new ultrasonic and laser supported technologies of machining.

Automatic monitoring of energy consumption in complex machining systems is indispensable in order to obtain energy consumption data, which are essential for proper evaluation, analysis and support of energy saving strategies.

In machining, several types of energy monitoring of machine tools have been developed $[4,5,6]$. Dornfeld et al. [4] used event stream processing techniques to develop an approach to automatic energy monitoring of machine tools. Hu et al. [7] developed an on-line approach to energy efficiency monitoring of machine tools without using a dynamometer. Diaz et al. [8] performed energy consumption characterization and reduction strategies for milling machine tools. Behrendt et al. [9] examined monitoring achievements in machining. Zhao et al. [10] explained in detail how to develop an energy efficiency system for monitoring machine tools. Kim et al. [11] proposed an energy consumption monitoring system for each axis of a machining center. Tristo et al. [12] introduced real time power consumption monitoring for performing an energy efficiency analysis in micro EDM milling. Lenz et al. [13] presented the implementation of energy monitoring on a component basis of a milling machine tool. Gong et al. [14] developed a hydraulic CNC machine tool monitoring system based on the intelligent embedded theory. $\mathrm{Wu}$ et al. [15] proposed a configurable on-line energy consumption monitoring system for machine tools. Jia [16] introduced energy efficiency state identification in milling processes based on information reasoning and the hidden Markov model. Liang et al. [17] developed an artificial neural network for energy consumption modelling and energy consumption monitoring. Cai et al. [18] established a strategy for monitoring the energy efficiency state and proposed the identification of energy efficiency state based on continuous wavelet transform.

Literature review revealed also recent studies which are related to energy consumption/efficiency monitoring in machining based on the emerging Internet of Things (IoT) technology. For example, Zheng et al. [19] introduced a concept and framework for smart energy consumption monitoring in machining. Chen et al. [20] in his paper briefly explained a framework for energy monitoring of machining workshops based on IoT. Chen et al. [21] developed an IoT-based energy efficiency monitoring and management system for machining workshops. An industrial application is presented to validate the effectiveness of the proposed system. This system was developed based on the general framework of the energy monitoring and management system developed by Shrouf et al. [22]. Liang et al. [17] introduced a framework of a cyber physical system for the optimization of energy efficient machining. 
Another approach to improve the energy efficiency of tool making companies is to introduce a labelling system that can classify machining equipment and processes according to their energy consumption. Namely, there are no specific regulations for machine tools and machining processes. This system will increase the efficiency of the future machining processes. This applies especially to small and medium-sized enterprises which buy state-ofthe-art machine tools based on the maximum machining capacity to machine with no precise assessment of actual requirements. Usually these machine tools are over-engineered and contain many advanced functions and additional systems that require additional electrical power. In machine tools, the chipping process accounts for a maximum of $25 \%$ of the total consumed energy [23]. The research carried out by Toyota [23] outlines that an average amount of energy used for the machining process makes only around $15 \%$ of the total energy consumption (Fig. 1). The majority of energy is consumed by additional equipment. Fig. 1 shows results of the analysis of the energy consumed in the machining process carried out in Toyota.

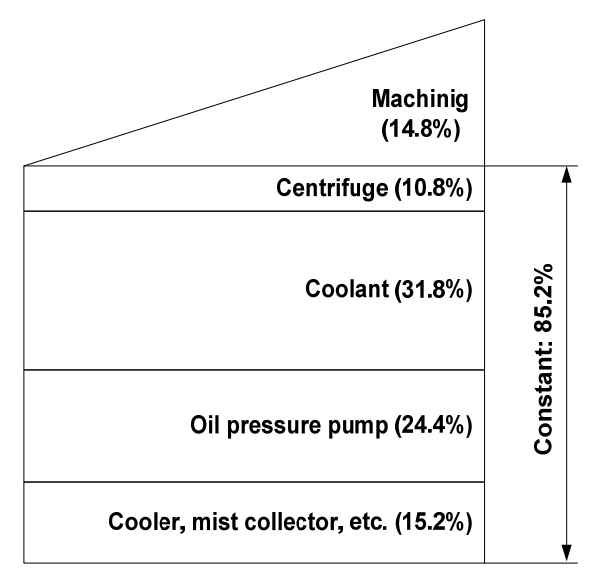

Fig. 1 Results of analysis of energy consumed in machining process [23]

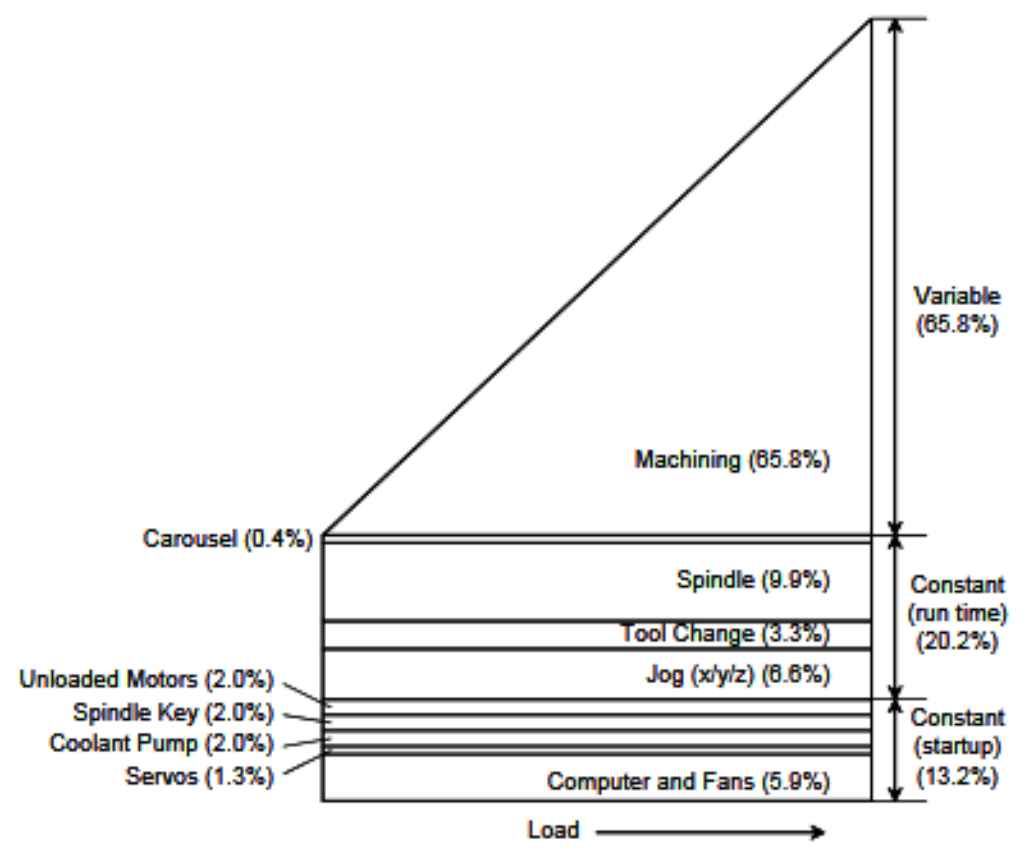

Fig. 2 Results of analysis of energy consumption in Bridgeport milling machine [2] 
New machine tools with similar equipment and basic functions are more energy efficient than older ones. Fig. 2 presents results of the analysis of energy consumption in a milling machine with a $6 \mathrm{~kW}$ spindle motor [2]. The chipping process carried out by this machine tool consumes $65.8 \%$ of the total process energy. A ten-year-older milling machine with similar equipment and basic functions consumes about $50 \%$ energy for performing the chipping process.

Energy efficiency of a manufacturing process is defined as a ratio of the product output to the total energy input. It is also known as the thermodynamic input-output energy efficiency. Due to many state-of-the-art subsystems in machine tools, the definition of energy efficiency in this form is not appropriate and efficient for machining. Therefore, several other indicators for energy efficiency of machine tools are proposed.

Thiede et al. [24] defined energy efficiency of a machine tool as a ratio between machined pieces and electrical power demand multiplied by machining time. According to Liu et al. [25], machine tool efficiency is a ratio of material effective (cutting) power to the machine input power.

After reviewing the literature, it was found that nowadays a lot of researchers $[26,27$, 28] employ the specific energy consumption (SEC) for evaluating the energy efficiency of machine tools. SEC represents the energy which is required to remove a specific volume of material. SEC is also defined as a ratio of cutting force to cutting chip cross section. Ma et al. [29] evaluated the energy efficiency of the metal cutting process with numerical simulations using the finite element method. In some studies, the energy efficiency of machine tools was evaluated with only one energy indicator (SEC); in others, a combined approach was applied, taking energy efficiency, environment, ecological and technical factors into account.

Xie et al. [28] reported that energy consumption models of machine tools are essential for improving energy efficiency in machining.

The literature review also revealed that the developed energy consumption models could be divided into three groups according to their structure and application properties.

Linear energy consumption models belong to the first group. These models rapidly determine the linear relationship between the material removal rate (MRR) and the SEC in order to predict the cutting energy consumption [30]. Kara et al. [31] developed empirical SEC models for milling and turning. In the developed models power is inversely proportional to the MRR. The model accuracy was above 94\%. Li et al. [32] introduced an improved SEC model that takes the speed of the spindle into account. The developed model prediction accuracy was $95 \%$.

The second group includes energy consumption correlations models that analyze the relation between energy consumption and parameters of the machining process. Researchers employed tool wear [28, 33, 34], material properties [35] cutting force [23, 36] and cutting parameters $[37,38]$ in the process of modelling energy consumption in milling. Luan [36] develop a relatively precise power prediction model based on the infinitesimal cutting force during the face milling process.

The third group of models consists of machining energy consumption models that are process-oriented [30]. Yoon et al. [39] developed a machine-based power consumption model to cope with a wide variety of machine tool configurations. Balogun et al. [40] built a model which considers energy consumption of the tool change process. Lv et al. [41] developed a model that takes all elements of the machine tool (power module, cooling, chip removal system, spindle system, feed system, lighting...) into account when modelling energy consumption. Lee et al. [42] estimated milling energy consumption based on anNC programming code. Liu et al. [43] built a model based on the assumptions that the main drive system was the main consumer of energy. 
Some models of cutting energy consumption were developed by using empirical formulas [43, 44, 45] or methods of experimental data mining, e.g. mathematical statistics $[23,46]$, surface response method, interpolation method and artificial neural network. Liang et al. [17] developed an artificial neural network for energy consumption modelling and energy consumption monitoring. Triebe et al. [47] investigated energy consumption of a machine tool through energy mapping. Nas et al. [48] performed the optimization of surface roughness applying the Taguchi method and the investigation into the energy consumption in the process of milling spheroidal graphite cast iron materials.

However, all the mentioned models are developed for a specific machine tool configuration. Therefore, a more general procedure is required that will enable comparison of new subtractive, formative and additive processes. The statistical and mathematical modelling must be replaced with new standards that measure and analyse the machine tool energy efficiently [30].

According to [30], it is necessary to introduce a more scientific and practical evaluation index system for assessing and testing energy efficiency of modern machine tools with complex subsystems.

Therefore, this paper introduces a non-dimensional EECI of energy efficiency that can be applied to classifications of processes, machine benchmarks without limitations to the considered technology and to the improvement of the cost-benefit relationship in production.

A comparative analysis of energy consumption based on the newly introduced EECI could accelerate energy saving procedures. This method analyses the machine tool efficiency with respect to energy consumption and classifies products of a machine tool manufacturer in relation to their competitors $[49,50,51]$.

It will be shown that based on the energy and cutting force measurements during machining, a simple EECI comparison enables us to identify the optimum process parameters that decrease energy consumption and improve productivity.

The paper is organized as follows. In the first part of this paper, a basic framework for a two-level platform for energy consumption monitoring and comparison of machining processes is presented. The next four sections describe the principal building block of the monitoring platform. The machining tests with results of the analyses are presented in Section 7. Section 8 concludes the paper.

\section{Platform for energy consumption monitoring and comparison of machining processes}

The objective of this study is to develop a smart monitoring platform for energy consumption monitoring in machining processes using a newly introduced EECI. The objective of the monitoring platform is to compare energy efficiencies of machine tools performing arbitrary machining operations. Its structure is depicted in Fig. 3. It consists of two main parts that are linked together through the Internet connection (LAN).

The first part consists of psychical elements and adequate software. The physical elements are the machine tool, cutting tools, cutting force sensors, a sensor for energy consumption measurements, hardware for signal acquiring and pre-processing and a terminal for data acquisition.

The cloud part is referred to as a cloud monitoring platform and consists of three applications and a gateway. The gateway objective is to execute the edge computing activities, such as security execution, communication establishing, data collecting and signal filtering. The gateway collects signals from the data acquisition terminal and applies them to the applications for energy consumption monitoring. 


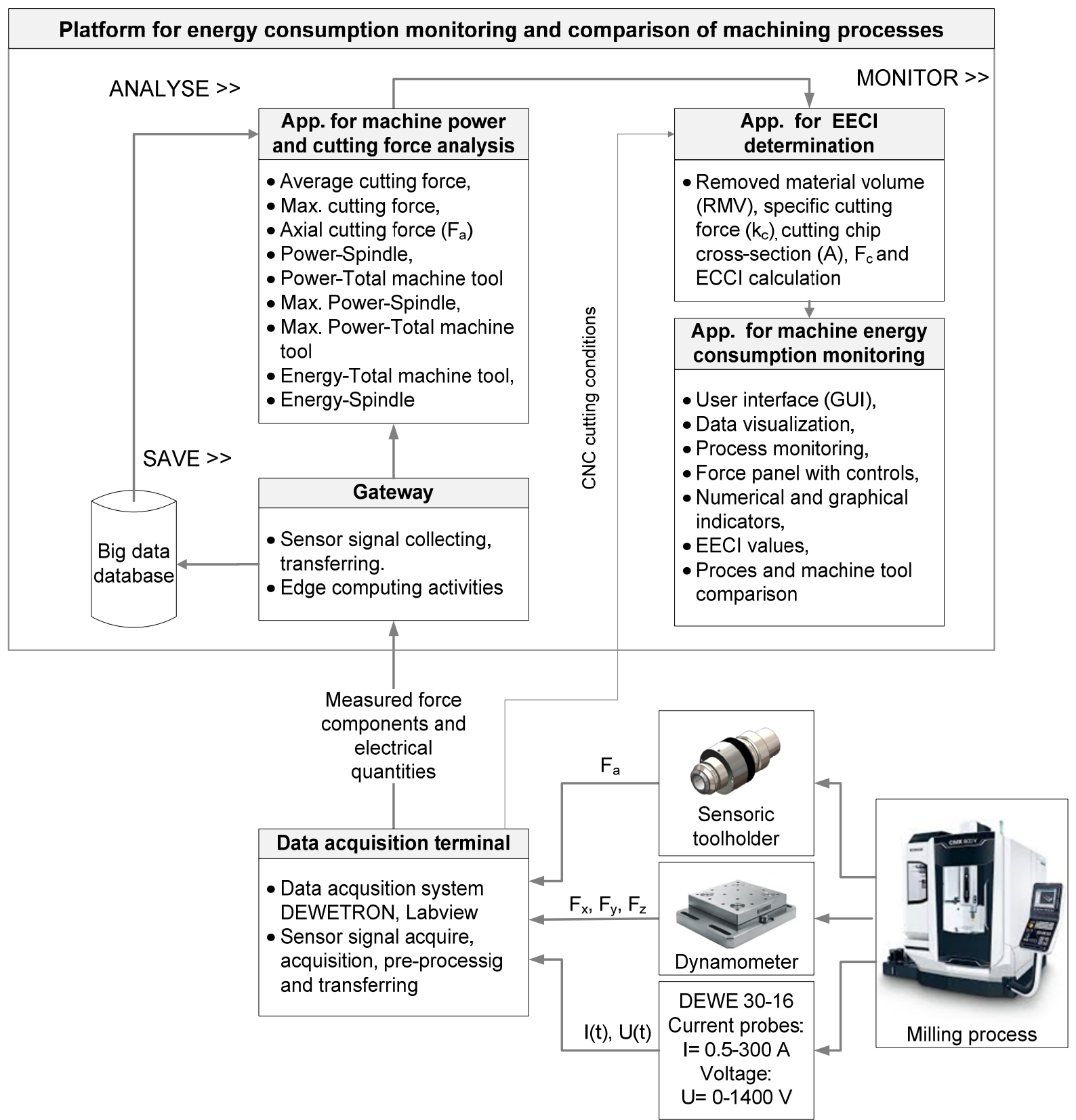

Fig. 3 Basic framework of two-level platform for energy consumption monitoring and comparison of machining processes

The applications process the signals further, extract features relevant for energy consumption monitoring, save the data, arrange the data, perform the data analysis, calculate the EEIC and visualize the analysis results. The individual applications are described in the following sections.

To perform the total monitoring of the machine tool or the machined tool subsystem energy consumption, the following steps have to be executed:

>>>> Machine tool, sensors, data acquisition terminal $>>>>$

1. Measurement of cutting force, voltage, current, axial torque and bending in the $\mathrm{x}$ and the y direction, signal acquisition, pre-processing and transmission to the gateway.

2. Establishment of a connection to the gateway.

$>>>>$ machine tool energy consumption monitoring platform $>>>$

3. Execution of the edge computing activities. 
4. Extraction of the cutting force signal feature, computation of average electrical power for the total machine tool or its subsystem, calculation of electrical energy consumption of the total machine tool or its subsystem, calculation of the specific cutting force, obtaining of the $\mathrm{CNC}$ cutting condition, calculation of the cutting force $F_{c}$, determination of the removed material volume, calculation of the cutting chip cross section.

5. EECI determination.

6. Graphical representation of the data analysis results.

7. Energy consumption monitoring and comparison.

8. Displaying of the monitoring results in a graphical form.

9. Projecting of the monitoring results back to the data acquisition terminal.

10. Steps 1 to 10 are repeated until the monitoring process is terminated.

\section{Application for the analysis of machine tool power and cutting force}

In this application, the software calculates the average and the maximal cutting force from the pre-processed data obtained by a wireless measurement system SPIKE and a stationary Kistler piezoelectric dynamometer. The software also determines the electrical power and the energy consumption of the machine tool in the time domain. The average and/or maximal electrical power and energy consumption is determined for both the spindle system and the whole machining process.

The determined values of the consumed electrical power, energy and extracted cutting force features are transmitted to the application for the EECI determination and to the energy consumption monitoring panel. The transmitted values are directly connected to the numerical and graphical indicators on the monitoring panel.

\section{Application for EECI determination}

This application is a fundamental part of the energy consumption monitoring platform. Most previous studies were focused only on the total consumed energy of processes as a relevant and accurate measure of energy efficiency. However, the researchers [30] reported that this multi-digit measure is not practical and suitable for assessing and testing energy efficiency of new technologies. Furthermore, the energy used for the machining process amounts to about 15 percent of the total machine tool energy consumption. Therefore, the total consumed energy value is not appropriate for classifying processes according to their energy consumption. Therefore, this application employs a novel EECI as a simple, practical and efficient number in order to evaluate/compare the energy efficiency of processes. The EEIC could be used to form a labelling (index) system similar to the system that classifies typical energy consuming products on the market (computers, lamps, refrigerators...) according to their energy consumption.

The new non-dimensional EECI indicator with its high potential of simplicity, expressiveness and versatility relates the specific consumed energy to a material constant. The inclusion of the process property simplifies the comparability of different subtractive, formative and additive processes. In all three cases the energy demand for a specific set of operations is related to the multiplication of the removed, formed or 3D-printed volume with a significant material property. Concerning a forming process, the deformed volume and the yield stress are used for the EECI calculation. The EECI for a selective laser melting process is calculated based on consumed energy, printed material volume and tensile strength. The tensile strength correlates with the linking forces between the atoms and the melting temperature of a material that mainly determines the necessary laser power. 
The EECI for machining is calculated based on consumed electrical energy (E), a removed metal material volume (RMV) and a specific material property $(\mathrm{k})$ of the machining process. In machining, the specific cutting force $\left(k_{\mathrm{c}}\right)$ is selected as the specific material constant $\mathrm{k}$. Therefore, the goal of the machining process optimization is to minimize the value of the EECI and thus to reduce the energy consumption for the specific RMV and $k_{\mathrm{c}}$.

The EECI for the milling process is calculated according to the formula:

$$
E E C I=\frac{E}{R M V \cdot k_{c}} .
$$

$k_{\mathrm{c}}$ is a function of material properties, type of milling, cutting speed, cutting tool geometry and the contact condition between the cutting tool and the machined material. In this study, the specific cutting force $k_{\mathrm{c}}$ is determined experimentally by calculating the average cutting force $F_{c}$ and dividing the obtained value by an average cutting chip cross section (A). The approximate magnitude of the specific cutting force $k_{\mathrm{c}}$ is calculated by the following equation:

$$
k_{c}=\frac{F_{c}}{A} .
$$

The measured cutting force components $F_{x}(\varphi)$ and $F_{y}(\varphi)$ are required to calculate the instantaneous tangential cutting force $F_{c}(\varphi)$ at the instantaneous immersion angle $\varphi$. The instantaneous values of $F_{c}(\varphi)$ are calculated according to:

$$
F_{c}(\varphi)=F_{x} \sin \varphi-F_{y} \cos \varphi
$$

Next, the average cutting force $F_{c}$ is obtained by summing the calculated instantaneous cutting forces $F_{c}(\varphi)$ and dividing the obtained value by the immersion zone $\left(\varphi_{\mathrm{st}} \leq \varphi \leq \varphi_{e x}\right)$.

The average cutting force $F_{c}$ is calculated as:

$$
F_{c}=\frac{\sum_{s t}^{\varphi_{e x}}\left(F_{x} \sin \varphi-F_{y} \cos \varphi\right)}{\varphi_{e x}-\varphi_{s t}} ; \quad \varphi_{e x} \leq \varphi \leq \varphi_{s t}
$$

where $\varphi_{\text {st }}$ is the starting and $\varphi_{\text {ex }}$ is the exit angle of immersion or engagement.

The cutting force components acting on a cutting tooth in milling are presented in Fig. 4.

The average cutting chip cross section is calculated from the engagement zone as:

$$
A=a_{p} \cdot \frac{\int_{\varphi_{s t}}^{\varphi_{e x}} 2 \cdot f_{z} \cdot \sin \varphi \mathrm{d} \varphi}{\varphi_{e x}-\varphi_{s t}}=-a_{p} \cdot 2 f_{z} \frac{\cos \varphi_{e x}-\cos \varphi_{s t}}{\varphi_{e x}-\varphi_{s t}}=\frac{2 \cdot a_{p} \cdot a_{e} \cdot f_{z}}{\left(\varphi_{e x}-\varphi_{s t}\right) \cdot d}
$$

where $a_{p}$ is the axial depth of cutting or the edge contact length, $a_{e}$ is the cutting width [mm], $d$ is the cutting tool diameter [mm] and $f_{z}$ is the feed rate [mm/rev-tooth].

The removed metal material volume is calculated using equation 6 .

$$
R M V=a_{p} \cdot a_{e} \cdot v_{f} \cdot t
$$

where $v_{f}$ is the feed rate $[\mathrm{mm} / \mathrm{s}]$ and $t$ is the machining time [s]. 


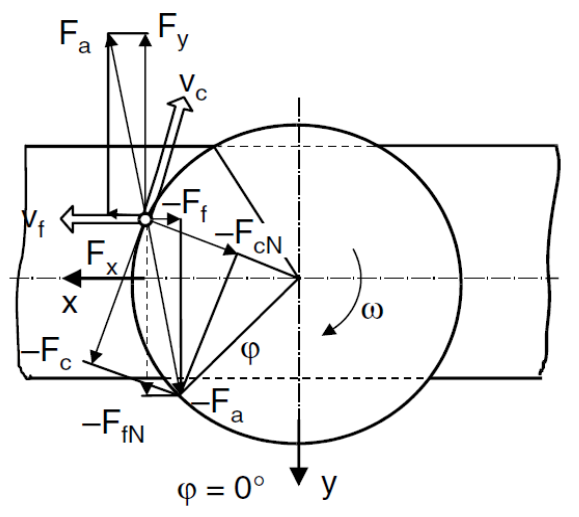

Fig. 4 Cutting force components on cutting tooth in milling [52]

\section{Application for monitoring machine tool energy consumption}

This part of the monitoring platform is designed as a human interface with an objective to graphically represent results of the data analysis and thus to simplify the monitoring process of the machine tool energy consumption. It simplifies the comparison process between milling processes and serves as a monitoring panel. The input to the software are the measured cutting forces with corresponding cutting conditions, the measured current, the measured voltage, the determined energy consumption of the machine tool component or machining process and the EECI.

Fig. 5 shows the user interface (GUI), referred to as the PAFA software. It consists of three dislocated elements. The first element with numerical indicators is located at the top of the GUI. The force panel with controls is located at the right-hand side. The centre element of the GUI graphically displays the determined power and cutting force values.

\section{Data acquisition terminal}

A personal computer (PC) is employed to acquire and pre-process signals from the two cutting force sensors and from the power measurement system. These pre-processed signals are then transferred to the cloud-based energy consumption monitoring platform. The data acquisition system Dewetron is installed on the PC, therefore the PC is referred to as the local data acquisition terminal (DAT). The Dewetron system is used to perform electrical power measurements. It consists of the main DEWE 30-16 device with 12 modules for measuring current or voltage with the sampling rate of up to $2 \mathrm{MHz}$. The energy consumption is determined both for the main spindle and for the entire machine tool. The consumed energy (E) is represented by the surface under the electrical power curve (Fig. 6). The momentary electrical power $P(t)$ of the machine tool component is determined as a product between the measured momentary current $I(t)$ and the voltage $U(t)$ for each phase (Fig. 6). The measurements were performed according to the electrical wiring diagram shown in Fig. 7 [53].

The cutting force components $\left(F_{x}, F_{y}, F_{z}\right)$ were measured by a Kistler 9257 piezoelectric dynamometer, a Kistler 5001 three-channel charge amplifier and a PC-based data acquisition system (Labview). Signals from the dynamometer were pre-processed, which includes signal amplification, signal filtering, A/D conversion and signal segmentation. The signal preprocessing was carried out on the data acquisition terminal (DAT). The DAT pre-processed the acquired signals into signal data packages and transferred them to the cloud-based monitoring platform. All signals were pre-processed by subtracting air cut signals and only the relevant part of the acquired signals was transferred to the application for carrying out analyses of the machine power and cutting force. In this cloud application, the transferred signal segments were then processed further 


\section{F.1. Power and Force Analysis}

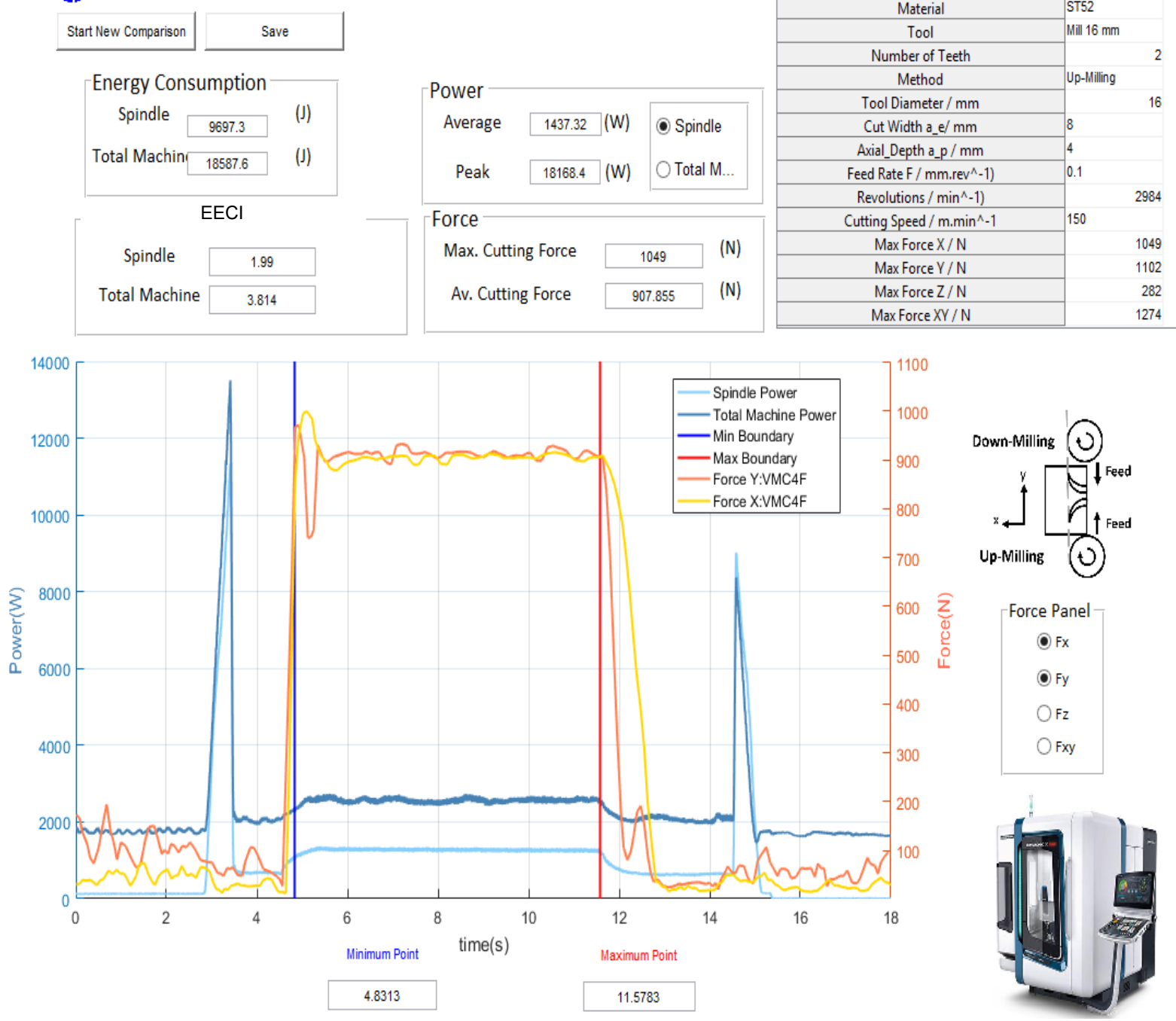

Fig. 5 Control panel for energy consumption monitoring and comparison of machining processes

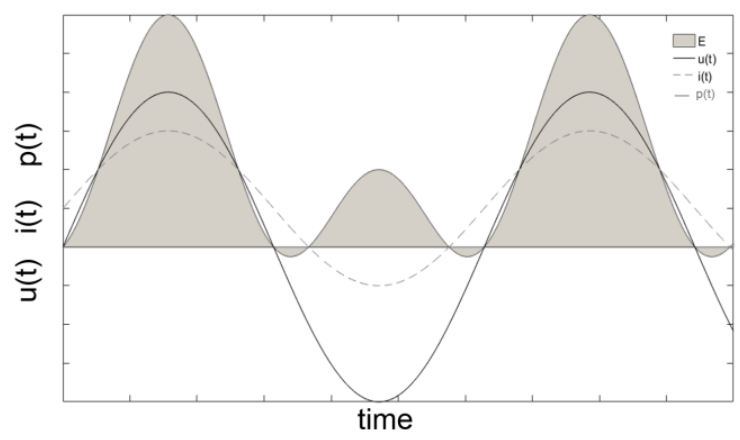

Fig. 6 Electrical quantities in time domain [53]

to extract signal features, such as peak-to-peak, signal mean and signal maximum and maxmin range. Signals from the dynamometer were conditioned with a dual mode charge amplifier (Kistler-Type 5001) and a low pass filter of $1 \mathrm{kHz}$ cut-off frequency. A one-pole passive filter with the second order Butterworth characteristic was integrated in the charge amplifier. It was configured to $1 / 3$ of the dynamometer natural frequency. The force signal was then transferred to a NI 925A card, which was controlled by the Labview software. The force measurements were sampled at $40 \mathrm{kHz}$. 
Based on the tooth passing frequency, enough information should be obtained in order to generate a discrete signal representing every single angle (from $0^{\circ}$ to $360^{\circ}$ ) the cutting insert goes through during the cutting process. According to the employed rotational spindle speed $n\left[\mathrm{~min}^{-1}\right]$ the minimum force sampling frequency $v_{\min }[\mathrm{Hz}]$ is defined as

$$
v_{\min }=\frac{n}{60} \cdot 360=n \cdot 6
$$

To avoid the distortion of the cutting force signal due to a small amount of noise, the tooth passing frequency has to be more than three times lower than the first natural frequency of the dynamometer. A $2984 \mathrm{~min}^{-1}$ spindle speed with a 2-tooth cutter yields the cutting frequency of $99.5 \mathrm{~Hz}$. Therefore, to measure the cutting force at the spindle speed of $2984 \mathrm{~min}^{-1}$ the natural frequency of the dynamometer must be higher than $298 \mathrm{~Hz}$. The frequency bandwidth of the employed dynamometer is therefore adequate for all machining conditions in this study.

The axial cutting force $F_{a}$ and the cutting tool deflection in both directions were measured by using the Spike system. The system is based on a wireless technology and is mounted to the spindle (see Fig. 8).
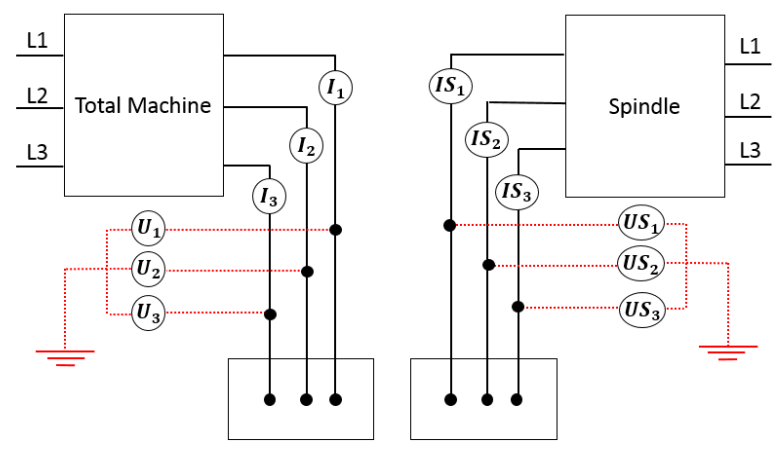

Fig. 7 Electrical wiring diagram of electrical power measurements

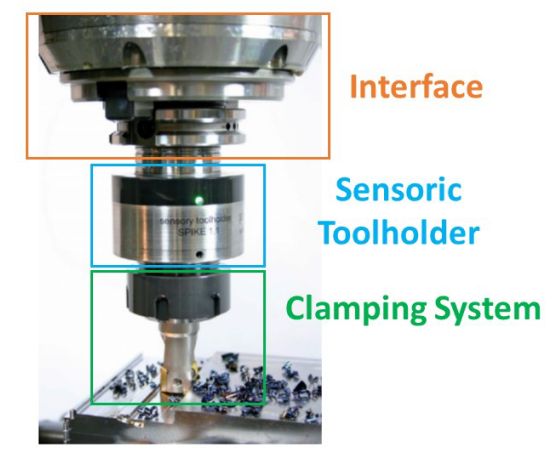

Fig. 8 Spike system mounted to the spindle [54]

\section{The results of experimental testing}

This chapter presents the results of three machining experiments. The efficiency of the machine tool energy consumption monitoring which uses the EECI is tested on a full slot milling of a St-52 steel workpiece.

The objective of the first machining tests was to compare the energy efficiency of the two machine tools performing an identical machining operation. The tested CNC milling machine tools are modern DMG MORI and VMC600. A cutting tool of a $16 \mathrm{~mm}$ in diameter with two flutes was used in the experiment. The feed rate was set to $0.01 \mathrm{~mm} /$ tooth and the 
axial depth of cutting was set to $2 \mathrm{~mm}$. The spindle speed was set to $2984 \mathrm{rpm}$ in order to achieve the cutting speed of $150 \mathrm{~m} / \mathrm{min}$.

The results of the comparison of the machine tools are presented in Table 1 . The results indicate that the modern 5-axis DMG milling machine with advanced features, such as high pressure cooling and ultrasonic milling function, requires more energy than the older milling machine. However, it should be emphasized that the main spindle of the modern DMG milling machine consumes much less energy when removing the same material volume. The RMV of $645.6 \mathrm{~mm}^{3}$ with an average cutting chip cross section of $0.0127 \mathrm{~mm}^{2}$ was identified during 20.28 seconds of the cutting process. The RMV was determined by using equation 6 . A for the $180^{\circ}$ engagement zone $\left(0^{\circ} \leq \varphi \leq 180^{\circ}\right)$ was calculated according to equation 5 . The determined value of $F_{c}$ for the DMG MORI milling machine was $53.6 \mathrm{~N}$. $F_{c}$ was determined based on the measured cutting forces $F_{x}(\varphi)$ and $F_{y}(\varphi)$ that were inserted into equation 4 . The determined $F_{c}$ for the VMC600 milling machine was slightly lower $(48.2 \mathrm{~N})$, which resulted in the calculated $k_{c}$ being $10 \%$ lower than $k_{c}\left(4204.3 \mathrm{~N} / \mathrm{mm}^{2}\right)$ in the DMG milling machine. The approximate (effective) $k_{c}$ is calculated according to equation 2 .

Table 1 Results of machine tool comparison with the determined EECI

\begin{tabular}{|lcc|}
\hline CNC milling machine & DMG MORI & VMC600 \\
\hline$F_{c}[\mathrm{~N}]$ & 53.6 & 48.2 \\
Time of machining [s] & 20.28 & 20.28 \\
E-spindle [J] & 6406 & 12069 \\
E-total machine tool [J] & 44003 & 29171 \\
P-spindle [W] & 316 & 595 \\
P-total machine tool [W] & 2169 & 1438 \\
Max. P-spindle [W] & 7516 & 11186 \\
Max. P-total machine tool [W] & 7809 & 13806 \\
RMV [mm ${ }^{3}$ ] & 645.6 & 645.6 \\
$k_{c}\left[\mathrm{~N} /\right.$ mm $^{2}$ ] & 4204.3 & 3784.1 \\
EECI-spindle & 2.36 & 4.94 \\
EECI-total machine tool & $\mathbf{1 6 . 2 1}$ & $\mathbf{1 1 . 9 4}$ \\
\hline
\end{tabular}

The objective of the second machining tests was to compare the energy efficiency of two different machining processes/operations through the EECI calculation. The machining operations with two different RMVs were performed and compared on the VMC600 machine tool. In the first experiment, the axial depth of cutting $\left(a_{p}\right)$ was set to $2 \mathrm{~mm}$, and in the second experiment, the axial depth of cutting was set to $4 \mathrm{~mm}$. The feed rate and the radial depth of cutting were the same as in the first machining test. The spindle speed was set to $2387 \mathrm{~min}^{-1}$.

The results of the comparison of the machining processes (different RMVs) are presented in Table 2. As expected, the results reveal that the lower values of the EECI were obtained for both the total machine tool and the spindle when machining with the higher RMV. According to equation 1, different cutting volumes are considered by the EECI calculation; therefore the lower EECI for both the spindle and the whole machine gives a reasonable decision support.

In the first experiment $\left(a_{p}=2 \mathrm{~mm}\right.$ ), the RMV of $331.04 \mathrm{~mm}^{3}$ with an average chip cross section of $0.0127 \mathrm{~mm}^{2}$ was identified during 13 seconds of cutting. In the second experiment $\left(a_{p}=4 \mathrm{~mm}\right)$, the RMV of $500.63 \mathrm{~mm}^{3}$ with an average chip cross section of $0.025 \mathrm{~mm}^{2}$ was identified during 9.83 seconds of cutting. $F_{c}$ determined in the experiment with the larger RMV was by $101 \%$ higher than $F_{c}$ determined in the experiment with the lower axial depth of cutting. The obtained magnitude of the specific cutting force $k_{c}$ for $a_{p}=2 \mathrm{~mm}$ was $4175 \mathrm{~N} / \mathrm{mm}^{2}$ and for $a_{p}=4 \mathrm{~mm}$ it was $4204 \mathrm{~N} / \mathrm{mm}^{2}$. 
Table 2 Results of comparison of machining processes (different RMVs).

\begin{tabular}{|lcc|}
\hline CNC milling machine & VMC600 & VMC600 \\
\hline$F_{c}[\mathrm{~N}]$ & 53.2 & 107.1 \\
Axial depth of cutting [mm] & 2 & 4 \\
Time of machining [s] & 13 & 9.83 \\
E-spindle [J] & 7620 & 9769 \\
E- total machine [J] & 19737 & 20542 \\
P- spindle [W] & 586 & 994 \\
P- total machine / [W] & 1518 & 2090 \\
Max. P-spindle [W] & 12895 & 15305 \\
Max. P-total machine [W] & 15030 & 18330 \\
RMV [mm ${ }^{3}$ ] & 331.04 & 500.63 \\
$k_{c}\left[\mathrm{~N} /\right.$ mm $\left.^{2}\right]$ & 4175 & 4204 \\
EECI-spindle & 5.513 & 4.641 \\
EECI-total machine & $\mathbf{1 4 . 2 8 0}$ & $\mathbf{9 . 7 5 9}$ \\
\hline
\end{tabular}

In the third machining test, the machining with two different cutting tools on the DMG machine tool was carried out. Two cutting tools of a $16 \mathrm{~mm}$ diameter with one and with two flutes were used to perform full slot milling. The feed rate was set to $0.02 \mathrm{~mm} /$ tooth and $\mathrm{a}_{\mathrm{p}}$ was set to $2.5 \mathrm{~mm}$. The spindle speed was set to $6963 \mathrm{~min}^{-1}$. The cutting conditions were identical in both the one-flute and the two-flute cutting tool experiment.

The objective was to compare the energy efficiency of the two milling processes that use cutting tools with different number of flutes. The machining with cutting tools that have different number of flutes leads to different machining times, different energy consumption and significantly different EECI values. The results of the comparison of the machining processes (different cutting tools) on the basis of EECI values are presented in Table 3.

The machining times were adjusted in order to achieve identical RMV and A in both experiments. The times of machining are presented in Table 3 . The results given in Table 3 indicate that the RMV was $2169 \mathrm{~mm}^{3}$ and A was $0.032 \mathrm{~mm}^{2} . F_{c}$ in the experiment with the two-flute cutting tool is slightly higher $\left(F_{c}=119.02 \mathrm{~N}\right)$ than in the experiment with the oneflute tool, where $F_{c}$ is $109.6 \mathrm{~N}$. Therefore, $k_{c}$ values determined in both experiments vary by $9 \%$.

Table 3 Results of comparison of machining processes (different cutting tools).

\begin{tabular}{|lcc|}
\hline CNC milling machine & DMG & DMG \\
\hline$F_{c}[\mathrm{~N}]$ & 119.02 & 109.60 \\
Number of flutes & 2 & 1 \\
Time of machining [s] & 11.68 & 23.36 \\
E-spindle [J] & 7400 & 15307 \\
E- total machine [J] & 31585 & 57402 \\
P- spindle [W] & 634 & 655 \\
P- total machine / [W] & 2704 & 2457 \\
Max. P-spindle [W] & 6336 & 6258 \\
Max. P-total machine [W] & 7031 & 6389 \\
RMV [mm $\left.{ }^{3}\right]$ & 2169 & 2169 \\
$k_{c}\left[N / m^{2}\right.$ ] & 3737 & 3441 \\
EECI-spindle & 0.913 & 2.051 \\
EECI-total machine & $\mathbf{3 . 8 9 7}$ & $\mathbf{7 . 6 9 1}$ \\
\hline
\end{tabular}




\section{Conclusion}

In this study, a smart platform for energy consumption monitoring in machining has been developed. The monitoring platform includes a unique electrical energy consumption indicator (EECI) and its purpose is to classify all machining operations and all machine tools without any restriction to the machine tool manufacturer, machine tool model or machining process. The EECI is obtained for the milling process by dividing the consumed electrical energy per removed material volume with the specific material constant.

The two-level monitoring platform consists of a machine tool, two cutting force sensors, a sensor for energy consumption measurements, equipment for signal acquiring and data acquisition and three cloud applications for energy consumption monitoring.

Three machining test cases have been presented to demonstrate the effectiveness of the proposed machine tool energy consumption monitoring and the potential of the newly introduced EECI as an energy efficiency evaluation and comparison measure of the machine tool and/or machining process.

In the first machining tests two different machine tools performing identical machining operations were compared. In the second tests the energy efficiency of two machining operations with different axial cutting depths were compared on the same machine tool. In the third machining test the energy efficiency of the two milling processes that use cutting tools with different number of flutes were compared.

The test results demonstrate that the proposed monitoring method using the EECI successfully evaluates and classifies machining processes, machine tools and machine tool subsystems in regard to energy efficiency.

The special interest of future activities is to employ the EECI as an international norm for machining processes and /or machine tools energy tagging.

In the future, more machining tests have to be done in order to perform more precise categorisation of both typical and special machine tools and/or machining processes such as, gear grinding, thread machining and laser assisted machining. Furthermore, the purpose of future activities will be to compare machining processes with significantly different input parameters in order to demonstrate the effectiveness of the introduced EECI.

The proposed monitoring approach with the EECI provides a novel way of energy consumption monitoring and energy efficiency evaluation in machining processes.

\section{REFERENCES}

[1] European Commission, Energy 2020, from

https:/ec.europa.eu/energy/sites/ener/files/documents/2011_energy2020_en_0.pdf, accessed August 11, 2016.

[2] Zein, A. (2012). Transition towards Energy Efficient Machine Tools, Berlin: Springer-Verlag, https://doi.org/10.1007/978-3-642-32247-1.

[3] Dahmus, J., Gutowski, T. (2004). Environmental analysis of machining. ASME International Mechanical Engineering Congress and Exposition, Manufacturing Engineering and Materials Handling Engineering, p. 643-652. https://doi.org/10.1115/IMECE2004-62600.

[4] Vijayaraghavan, A., Dornfeld, D. (2010). Automated energy monitoring of machine tools. CIRP annals, vol. 59(1), p. 21-24. https://doi.org//10.1016/j.cirp.2010.03.042.

[5] Mori, M., Fujishima, M., Inamasu, Y., Oda, Y. (2011). A study on energy efficiency improvement for machine tools. CIRP Annals-Manufacturing Technology, vol. 60(1), p. 145-148. https://doi.org//10.1016/j.cirp.2011.03.099.

[6] Avram, O. I., Xirouchakis, P. (2011). Evaluating the use phase energy requirements of a machine tool system. Journal of Cleaner Production, vol. 19(6-7), p. 699-711. https://doi.org//10.1016/j.jclepro.2010.10.010

[7] Hu, S., Liu, F., He, Y., Hu, T. (2012). An on-line approach for energy efficiency monitoring of machine tools. Journal of cleaner production, vol. 27, p.133-140. https://doi.org//10.1016/j.jclepro.2012.01.013 
[8] Diaz, N., Redelsheimer, E., Dornfeld, D. (2011). Energy consumption characterization and reduction strategies for milling machine tool use. In Glocalized solutions for sustainability in manufacturing (p. 263-267). Springer, Berlin, Heidelberg. https://doi.org//10.1007/978-3-642-19692-8_46

[9] Behrendt, T., Zein, A., Min, S. (2012). Development of an energy consumption monitoring procedure for machine tools. CIRP Annals-Manufacturing Technology, vol. 61(1), p. 43-46. https://doi.org//10.1016/j.cirp.2012.03.103.

[10] Zhao, G., Zheng, G., Xu, Y. (2013). Computer monitoring approach and system on machine tools energy efficiency. Sensors \& Transducers, vol. 161(12), p. 288,

[11] Kim, J. H., Nam, S. H., Lee, D. Y. (2015). Energy Consumption Monitoring System for Each Axis of Machining Center. Journal of the Korean Society for Precision Engineering, vol. 32(4), p. 339-344, https://doi.org/10.7736/KSPE.2015.32.4.339.

[12] Tristo, G., Bissacco, G., Lebar, A., Valentinčič, J. (2015). Real time power consumption monitoring for energy efficiency analysis in micro EDM milling. The International Journal of Advanced Manufacturing Technology, vol. 78(9-12), p. 1511-1521, https://doi.org/10.1007/s00170-014-6725-3.

[13] Lenz, J., Kotschenreuther, J., Westkaemper, E. (2017). Energy efficiency in machine tool operation by online energy monitoring capturing and analysis. Procedia CIRP, vol. 61, p. 365-369, https://doi.org//10.1016/j.procir.2016.11.202.

[14] Gong, D., Xu, F., Liu, J., Xuan, L. (2017). Intelligent Embedded Monitoring System of Hydraulic CNC Machine Tool. Chemical Engineering Transactions, vol. 62, p. 853-858, https://doi.org//10.3303/CET1762143.

[15] Wu, P., He, Y., Lim, M. K., Wang, Y., Wang, Y., Hu, L. (2018). A Configurable On-Line Monitoring System Towards Energy Consumption of Machine Tools. In Advances in Green Energy Systems and Smart Grid (p. 139-150). Springer, Singapore.

[16] Jia, S., Yuan, Q., Cai, W., Li, M., Li, Z. (2018). Energy modeling method of machine-operator system for sustainable machining. Energy Conversion and Management, vol. 172, p. 265-276, https://doi.org/10.1016/j.enconman.2018.07.030.

[17] Liang, Y. C., Lu, X., Li, W. D., Wang, S. (2018). Cyber Physical System and Big Data enabled energy efficient machining optimisation. Journal of Cleaner Production, vol. 187, p. 46-62, https://doi.org//10.1016/j.jclepro.2018.03.149

[18] Cai, Y., Shi, X., Shao, H., Yuan, J. (2019). Energy Efficiency State Identification Based on Continuous Wavelet Transform-Fast Independent Component Analysis. Journal of Manufacturing Science and Engineering, vol. 141(2), 021012, https://doi.org/10.1115/1.4041568.

[19] Zheng, P., Sang, Z., Zhong, R. Y., Liu, Y., Liu, C., Mubarok, K., Xu, X. (2018). Smart manufacturing systems for Industry 4.0: Conceptual framework, scenarios, and future perspectives. Frontiers of Mechanical Engineering, p. 1-14, https://doi.org//10.1007/s11465-018-0499-5

[20] Chen, X., Li, C., Tang, Y., Li, L., Xiao, Q. (2018a). A framework for energy monitoring of machining workshops based on IoT. Procedia CIRP, vol. 72, p. 1386-1391.

[21] Chen, X., Li, C., Tang, Y., \& Xiao, Q. (2018). An Internet of Things based energy efficiency monitoring and management system for machining workshop. Journal of Cleaner Production, vol. 199, p. 957-968, https://doi.org//10.1016/j.jclepro.2018.07.211.

[22] Shrouf, F., \& Miragliotta, G. (2015). Energy management based on Internet of Things: practices and framework for adoption in production management. Journal of Cleaner Production, vol. 100, p. 235-246, https://doi.org//10.1016/j.jclepro.2015.03.055

[23] Draganescu, F., Gheorghe, M., Doicin, D. (2012). Models of machine tool efficiency and specific consumed energy. Journal of Material Processing Technology, vol. 141(1), p. 9-15, https://doi.org/10.1016/S0924-0136(02)00930

[24] Thiede, S. (2012). Energy efficiency in manufacturing systems. Springer Science \& Business Media.

[25] Liu, F., Wang, Q., Liu, G. J. (2013). Content architecture and future trends of energy efficiency research on machining systems. Journal of Mechanical Engineering, vol. 49(19), p. 87-94.

[26] Balogun, V. A., Edem, I. F., Adekunle, A. A., Mativenga, P. T. (2016). Specific energy based evaluation of machining efficiency. Journal of cleaner production, vol. 116, p. 187-197, https://doi.org//10.1016/j.jclepro.2015.12.106.

[27] Zhao, G. Y., Liu, Z. Y., He, Y., Cao, H. J., Guo, Y. B. (2017). Energy consumption in machining: Classification, prediction, and reduction strategy. Energy, vol. 133, p. 142-157, https://doi.org//10.1016/j.energy.2017.05.110 
[28] Xie, J., Liu, F., Qiu, H. (2016). An integrated model for predicting the specific energy consumption of manufacturing processes. The International Journal of Advanced Manufacturing Technology, vol. 85(58), p. 1339-1346, https://doi.org//10.1016/j.energy.2017.05.110.

[29] Ma, J., Ge, X., Chang, S. I., Lei, S. (2014). Assessment of cutting energy consumption and energy efficiency in machining of 4140 steel. The International Journal of Advanced Manufacturing Technology, vol. 74(9-12), p. 1701-1708, https://doi.org/org/10.1007/s00170-014-6101-3.

[30] Zhou, L., Li, J., Li, F., Meng, Q., Li, J., Xu, X. (2016). Energy consumption model and energy efficiency of machine tools: a comprehensive literature review. Journal of Cleaner Production, vol. 112, p. 37213734, https://doi.org/10.1016/j.jclepro.2015.05.093.

[31] Kara, S., Li, W. (2011). Unit process energy consumption models for material removal processes. CIRP Annals-Manufacturing Technology, vol. 60(1), p. 37-40. https://doi.org//10.1016/j.cirp.2011.03.018

[32] Li, L., Yan, J.H., Xing, Z.W. (2013). Energy requirements evaluation of milling machines based on thermal equilibrium and empirical modeling. J. Clean. Prod. vol. 52, p.113-121.

[33] Liu, Z. Y., Guo, Y. B., Sealy, M. P., Liu, Z. Q. (2016). Energy consumption and process sustainability of hard milling with tool wear progression. Journal of Materials Processing Technology, Vol. 229, p. 305312, https://doi.org/10.1016/j.jmatprotec.2015.09.032.

[34] Shi, K. N., Zhang, D. H., Liu, N., Wang, S. B., Ren, J. X., Wang, S. L. (2018). A novel energy consumption model for milling process considering tool wear progression. Journal of Cleaner Production, vol. 184, p. 152-159.

[35] Meng, Y., Wang, L., Lee, C. H., Ji, W., Liu, X. (2018). Plastic deformation-based energy consumption modelling for machining. The International Journal of Advanced Manufacturing Technology, vol. 96(14), p. 631-641, https://doi.org//10.1007/s00170-017-1521-5.

[36] Luan, X., Zhang, S., Li, G. (2018). Modified power prediction model based on infinitesimal cutting force during face milling process. International Journal of Precision Engineering and Manufacturing-Green Technology, vol. 5(1), p. 71-80, https://doi.org//10.1007/s40684-018-0008-7.

[37] Imani Asrai, R., Newman, S. T., Nassehi, A. (2018). A mechanistic model of energy consumption in milling. International Journal of Production Research, vol. 56(1-2), p. 642-659, https://doi.org//10.1080/00207543.2017.1404160.

[38] Zhang, C., Zhou, Z., Tian, G., Xie, Y., Lin, W., Huang, Z. (2018). Energy consumption modeling and prediction of the milling process: a multistage perspective. Proceedings of the Institution of Mechanical Engineers, Part B: Journal of Engineering Manufacture, vol. 232(11), p. 1973-1985, https://doi.org/10.1177/0954405416682278.

[39] Yoon, H. S., Singh, E., Min, S. (2018). Empirical power consumption model for rotational axes in machine tools. Journal of Cleaner Production, doi.org/10.1016/j.jclepro.2018.06.028.

[40] Balogun, V. A., Mativenga, P. T. (2013). Modelling of direct energy requirements in mechanical machining processes. Journal of Cleaner Production, vol. 41, p. 179-186, https://doi.org//10.1016/j.jclepro.2012.10.015.

[41] Lv, J., Tang, R., Jia, S. (2014). Therblig-based energy supply modeling of computer numerical control machine tools. Journal of cleaner production, vol. 65, p. 168-177, https://doi.org//10.1016/j.jclepro.2013.09.055.

[42] Lee, J. Y., Shin, Y. J., Kim, M. S., Kim, E. S., Yoon, H. S., Kim, S. Y., Min, S. (2016). A simplified machine-tool power-consumption measurement procedure and methodology for estimating total energy consumption. Journal of Manufacturing Science and Engineering, vol. 138(5), 051004, https://doi.org/10.1115/1.4031713.

[43] Liu, F., Xie, J., Liu, S. (2015). A method for predicting the energy consumption of the main driving system of a machine tool in a machining process. Journal of Cleaner production, vol. 105, p. 171-177, doi.org/10.1016/j.jclepro.2014.09.058

[44] He, Y., Liu, F., Wu, T., Zhong, F. P., Peng, B. (2012). Analysis and estimation of energy consumption for numerical control machining. Proceedings of the Institution of Mechanical Engineers, Part B: Journal of Engineering Manufacture, vol. 226(2), p. 255-266. https://doi.org//10.1177/0954405411417673.

[45] Li, W., Kara, S. (2011). An empirical model for predicting energy consumption of manufacturing processes: a case of turning process. Proceedings of the Institution of Mechanical Engineers, Part B: Journal of Engineering Manufacture, vol. 225(9), p. 1636-1646. https://doi.org//10.1177/2041297511398541.

[46] Kara, S., Li, W. (2011). Unit process energy consumption models for material removal processes. CIRP Annals-Manufacturing Technology, vol. 60(1), p. 37-40. https://doi.org//10.1016/j.cirp.2011.03.018 
[47] Triebe, M. J., Mendis, G. P., Zhao, F., Sutherland, J. W. (2018). Understanding Energy Consumption in a Machine Tool through Energy Mapping. Procedia CIRP, vol. 69, p. 259-264, https://doi.org//10.1016/j.procir.2017.11.041

[48] Nas, E., Öztürk, B. (2018). Optimization of surface roughness via the Taguchi method and investigation of energy consumption when milling spheroidal graphite cast iron materials. Materials Testing, vol. 60(5), p. 519-525, https://doi.org//10.1016/j.procir.2017.11.041

[49] Zhou, J., (2013). Digitalization and intelligentization of manufacturing industry. Journal of Advances in Manufacturing Springer/Verlag, 1:1, p. 1-7, https://doi.org/10.1007/s40436-013-0006-5.

[50] Liu, Z. Y., Guo, Y. B., Sealy, M. P., Liu, Z. Q. (2016). Energy consumption and process sustainability of hard milling with tool wear progression. Journal of Materials Processing Technology, Vol. 229, p. 305312, https://doi.org/10.1016/j.jmatprotec.2015.09.032.

[51] Redecker, M., Haas, F., Schmiedhofer B. (2014). Energy optimized machine tools and processes with advanced measuring technology and evaluation, TMT2014 18th International Research/Expert Conference, p. 433-436, ISSN 1840-4944.

[52] Berend, D. et al. (2011) Spanen Grundlagen, Springer, Heidelberg, Germany. https://doi.org/10.1007/978-3-642-19772-7

[53] Paetzold, J., (2011) Messung elektrischer Energie - Grundlagen und Erfahrung in Methoden der energetisch-wirtschaftlichen Bilanzierung und Bewertung in der Produktionstechnik. Erkenntnisse aus dem Spitzentechnologiecluster eniPROD, 35-54. URN: http://nbn-resolving.de/urn:nbn:de:bsz:ch1qucosa-109067.

[54] Promicron, SPIKE, Sensory tool holder, from http://www.pro-micron.de/fileadmin/user_upload/Bilder/Produkte/SPIKE_-, accessed September 26, 2016.

Submitted: $\quad 29.10 .2018$

Accepted: $\quad 03.4 .2019$
Franz Haas

franz.haas@tugraz.at

Andres Suarez

andres.suarezg@outlook.com

Graz University of Technology, Institute

of Production Engineering

A-8010 Graz, Inffeldgasse 11.

Franci Cus

franc.cus@um.si

Uros Zuperl (corresponding author)

uros.zuperl@um.si

University of Maribor, Faculty of

Mechanical Engineering,

Smetanova 17, 2000 Maribor 